Mirai. Estudios Japoneses

ISSN-e: 2531-145X

http://dx.doi.org/10.5209/MIRA.60503

\title{
Sin dinero, sin pertenencias, sin dientes. Sólo yo. La génesis del haiku de ritmo libre y la poética de Taneda Santōka (1882-1940)
}

\author{
Yaxkin Melchy Ramos ${ }^{1}$
}

\section{FECHAS}

Resumen. Actualmente, el haiku de ritmo libre es una corriente popular en la poesía contemporánea japonesa. El artículo busca visualizar algunos de los ideales estéticos y espirituales que dieron forma al haiku de ritmo libre (jiyu ritsu haiku 自由律俳句). Estos ideales pueden enlazarse entre sí siguiendo la genealogía que va de Masaoka Shiki (1867-1902) a Ozaki Hōsai (1885-1926) y que tiene una de sus cimas en la poesía-vida de Taneda Santōka (1882-1940), uno de los poetas más celebrados en la actualidad. Después de un breve recuento histórico me centraré en lo que podría ser el punto de partida de un enfoque ecocrítico de la poética de Santōka en algunos de sus poemas y pasajes de diarios. Este enfoque nos ayuda a resaltar el desarrollo de una apreciación moderna de la naturaleza en la poesía japonesa, basada en la lucha del individuo por la autosuperación y el valor de la sinceridad del corazón. Palabras clave: Santōka; haiku; ecocrítica; ecopoética

[en] No money, no belongings, no teeth. Just me. The origins of free rythm haiku and the poetry of Taneda Santôka (1882-1940)

\begin{abstract}
Today the free rhythm haiku (jiy $\overline{\mathrm{u}}$ ritsu haiku 自由律俳句) is a popular trend in present-day Japanese literature. This paper brings to light the genealogy of aesthetic and spiritual ideals that goes from Shiki Masaoka (1867-1902) to Ozaki Hōsai (1885-1926) and that shaped the free rhythm haiku in Japan. This genealogy has one of its heights in the poetry-life of Taneda Santōka (1882-1940), one of the most recognized poets presently. After a short review of this genealogy, I will focus on Santōka's poetics, by translating some of his poems and passages from his diaries, to situate what could be the starting point for an ecocritical approach of his poetics. This approach highlights the development of an appreciation of the natural world from the point of view of the individual struggle for self-improvement and the moral value of sincerity of heart.
\end{abstract}

Keywords: Santōka; haiku; ecocriticism; ecopoetics.

Sumario: De Masaoka Shiki a Ozaki Hōsai. Suplicio en la poética de Santōka. Santōka y la naturaleza. Conclusiones.

Cómo citar: Melchy Ramos, Y. (2018). Sin dinero, sin pertenencias, sin dientes. Sólo yo. La génesis del haiku de ritmo libre y la poética de Taneda Santōka (1882-1940), en Mirai. Estudios Japoneses 2(2018), 175-188.

\footnotetext{
Egresado de la Maestría en Estudios de Asia y África del Colegio de México. yaxkinmex@gmail.com
} 
Los casi setenta años que van desde el periodo de la renovación Meiji (1868) hasta el inicio de la Guerra del Pacífico (1937) significaron, en el ámbito de la poesía, la transformación del estilo de vida de los poetas del haiku (haijin 俳人) y del circuito de producción y consumo de la poesía que había enraizado en la cultura japonesa durante el periodo Edo (1603-1868). Se trató de un periodo de inestabilidad social, cuestionamientos culturales y de adaptación al impulso modernizador encabezado por Europa y los Estados Unidos. Durante este periodo se dio forma a la manera de interpretar el formato poético del haiku como una "instantánea de la vida" y como un testimonio del momento de despertar o satori (悟り) enraizado en lo cotidiano. Por otra parte, se innovó la forma de entender el haiku y su creación, en parte debido a la influencia literaria europea que se tradujo en nuevos circuitos, y en parte debido poéticas personalísimas y excepcionales que dieron forma al haiku del siglo $\mathrm{XX}, \mathrm{y}$ más aún, a una apreciación moderna de la naturaleza.

Las primeras dos décadas del periodo Meiji (1868-87) revelan la preocupación del nuevo gobierno para asentar un estado nacional moderno, promoviendo para ello la centralización política, el desarrollo de las comunicaciones y transportes, la reforma tributaria y educativa, la apertura de universidades ${ }^{2}$ y la preparación de la Constitución de 1889. En el ámbito de las letras, los autores japoneses recibieron una gran influencia de la literatura europea y sus escuelas, las cuales se estudiaron, imitaron y adaptaron al son del lema progresista de la época: "Civilización e ilustración" (Bunmei kaika 文明開化).

El interés hacia las letras modernas europeas trajo consigo las primeras traducciones al japonés, y el debate sobre cómo mantener las tradiciones propias y a la vez instalar en el territorio las tradiciones extranjeras. Este debate, que iba a la par de otras transformaciones radicales en el país, produjo cambios inéditos en la concepción de la figura del poeta y la circulación de la poesía. Así, se generaron estéticas y actitudes discordantes, pero coexistentes. Mientras algunos poetas buscaron refugio en poéticas conservadoras, ${ }^{3}$ otros como Masaoka Shiki, ${ }^{4}$ Kawahigashi Hekigotō, ${ }^{5}$ Ogiwara Seisensui ${ }^{6}$, Ozaki Hōsai ${ }^{7}$ y Taneda Santōka ${ }^{8}$ llevaron la vía del haijin a nuevos circuitos de difusión y consumo como los periódicos y las revistas, a la vez que promovieron la idea de modernizar el espíritu del haiku. Los poemas, los diarios personales y las vidas de estos poetas nos muestran un periodo caracterizado por la dureza de la vida, la propensión a un sentimiento de soledad y culpa, la búsqueda de la intensidad de las emociones y la introducción de los medios de comunicación modernos que pusieron el énfasis en la individualidad del artista. El resultado fue la aparición de nuevas formas en la poética del haiku como el ritmo libre, la introducción de extranjerismos y la popularización de la idea del poema como una "instantánea

Durante este periodo se fundaron las principales universidades del país como la Universidad de Waseda (1882) y la Universidad de Tokio (1886).

3 Fuera de este impulso vanguardista, se tiene a poetas como Fukuda Kodōjin (1865-1944), originario de Shingū, Wakayama y también amigo y seguidor de Shiki, quien se dedicó al cultivo de la caligrafía y el haiga siguiendo los ideales de los textos japoneses y chinos de antaño. Su vida retirada en Kioto le dio la oportunidad de ahondar en una poesía basada en la apreciación de la naturaleza, el hombre y la serenidad, manteniendo los símbolos de lo cotidiano.

4 Masaoka Shiki 正岡 子規 (1867-1902).

5 Kawahigashi Hekigotō河東碧梧桐 (1873-1937).

6 Ogiwara Seisensui荻原 井泉水 (1884-1976).

7 Ozaki Hōsai尾崎 放哉 (1885-1926).

8 Taneda Santōka種田山頭火 (1882-1940). 
de la vida cotidiana" (shasei 写生). Estos cambios significaron también una nueva actitud frente a la caligrafía y de la integración del poema y la pintura en el formato haiga 俳画. En cuanto a la vía espiritual del haiku, se hizo una nueva interpretación de las obras de los maestros como Bashō y Buson, dando forma a una idea del haiku como el testimonio de un "despertar" en lo cotidiano, que se ha mantenido hasta la época reciente. ${ }^{9}$

Entre los poetas que dieron forma al haiku moderno, he pretendido visualizar la genealogía de ideales estético-espirituales del llamado haiku libre (o de nueva tendencia), que va de Masaoka Shiki a Ozaki Hōsai, y que alcanza una de sus cimas en la vida y poesía de Taneda Santōka, ${ }^{10}$ uno de los poetas más reconocidos en la actualidad. Después de un breve recuento de esta genealogía me centraré en la poética de Santōka, para ello traduzco algunos de sus poemas y pasajes de diarios, con el fin de situar lo que podría ser el punto de partida de un enfoque ecocrítico de su poética de lucha por la autosuperación.

\section{De Masaoka Shiki a Ozaki Hōsai}

Masaoka Shiki, originario de Matsuyama en la isla de Shikoku, fue probablemente el más influyente de los poetas y pensadores en la historia del haiku moderno. Nació dentro de una familia samurái modesta y desde sus años como estudiante en la escuela media (1880-1883) introdujo, entre su círculo de amigos aficionados a la literatura, las ideas sobre la esencia, el pasado y el futuro del haiku, que fueron recopiladas posteriormente en su Compendio del Haikai (Haikai taiyō 俳諧大要) de 1895. En esta obra declaraba: "El haiku es parte de la literatura. La literatura es parte el arte", ${ }^{11}$ trasladando así el haiku de su sustrato tradicional, al nuevo mundo de la literatura y el arte moderno. Con ello, buscaba una apertura de las formalidades del género a la vez que conservar la esencia del haiku, para ello promovió la idea de que su esencia se encontraba en el principio de una "instantánea de vida" o "esbozo" de la realidad que bautizó como shasei 写生. Shiki creó este neologismo a partir de una idea de origen chino que refiere al poema que es opuesto al ideal de "pintura de la idea o sentimiento" (shai 写意), que se popularizó en la época Edo. ${ }^{12}$

La idea del shasei fue forjada por Shiki tras su lectura de los poemas de Yosa Buson ${ }^{13}$ para describir los haikus que muestra la realidad "tal como es" (ari no mama ありのまま). Las ideas de Shiki abrevaron tanmbién de las propuestas naturalistas de la pintura europea como la de eliminar las experiencias fantásticas o que estaban consideradas producto de la imaginación. Con esta amalgama particular, Shiki defendía el haiku como un arte para "reflejar" los sucesos de la vida, o sea, como un tipo de arte verbal que profundiza en el presente concreto y sensorial. Las ideas de

9 El primero de ellos es el término haiku, utilizado hoy en día, que fue creado por el poeta y crítico literario Shiki Masaoka, quien además idealizó el haiku como un género poético de testimonio de súbitos estados de iluminación o satori (悟り).

10 A quien me refiero más Adelante sólo como Santōka su nombre de pila, más conocido entre los lectores.

11 Keene, Donald (2013): The Winter Sun Shines In. A Life of Masaoka Shiki. Nueva York: Columbia University Press, p. 93.

12 Vid. Addis, Stephen (2012): The Art of Haiku. Its History through Poems and Paintings by Japanese Masters. Boston: Shambala, pp. 267-282.

13 Yosa Buson与謝 囬村 (1716-1784). 
Shiki tuvieron tal repercusión que durante décadas influyeron en la interpretación de la poesía de Yosa Buson como un poeta de la "objetividad"14 e incluso, el entendimiento mismo del haiku como una vía mística forjada en el concepto de shasei:

"El yunque en el que se forja esta sensibilidad mística del japonés es la descripción pura, exacta, sin intromisiones del yo, de lo que sucede fuera del poeta; la atención plena al mundo que nos rodea. Lo que se llama en japonés "espíritu de shasei”. Shasei (写生) significa “esbozo del natural, describir lo que uno presencia”. Un haiku es una instantánea de la realidad. El haiku no transforma el mundo; te pone en contacto con él te lleva a él, te introduce en él. No explica la realidad, ni la embellece; la muestra." 15

Pese a la belleza que recupera y vigoriza de los grandes maestros la interpretación de Shiki, el mundo del haiku se ha mantenido siempre en constante movimiento y la interpretación de Shiki fue rebatida por los autores que le siguieron. En su tesis doctoral sobre la obra de Yosa Buson la literata Cherryl A. Crowley nos muestra que dos décadas después de la muerte de Shiki esta lectura que atribuía el principio del shasei a Buson había sido rebatida la poetisa Yosano Akiko en 1932. ${ }^{16}$

Akiko found Buson not to be a detached, objective poet as Shiki portrayed him,
but a romantic neo-classicist, moved by many of the same things she herself was.
Instead of a forerunner of modem realism, she viewed him as a throwback to an
earlier age both in terms of language and of thematic choices. The majority of her
essay consists of interpretations of individual hokku, and the ones that she chose
focus on Buson's monogatari (tale)-like verses, those in which he makes allusions
to Heian-period literature, and those constructed completely out of his imagina-
tion. She challenged the view of Buson as a shasei poet, and argued that he was
mainly driven by feeling. ${ }^{17}$

Estudios recientes como el de Crowley recuperan otras visiones de la poética de Buson a la luz de otros autores y descubrimientos recientes como una colección hecha por el propio autor (Buson jihitsu kucho無村自筆句帳). Por consiguiente, podemos decir que el ir y venir de las posturas sobre el shasei nos debería recalcar que quizá se trata sólo de uno entre varios ideales donde se forja la tradición del haiku; como apuntó el teólogo y traductor Antonio Cabezas, el haiku acoge distintas ideas, según los tiempos y los creadores que han dado forma a esta tradición: "no hay nada definido ni dogmático". ${ }^{18}$ Sin embargo, no debemos descuidar la importancia

$14 \quad C f$. Con la clásica antología en Occidente, Haiku de R.H. Blyth. Para el autor Buson representa el poeta que vive primeramente en el mundo fenoménico. Bцүтн, Reginald H. (1949): Haiku (en cuatro volúmenes), Tokio: Hokuseidō, p.340.

15 Haya, Vicente (2008): El Haikudō. El haiku como camino espiritual. España: Kairós. (versión en Kindle).

16 Akiko Yosano 与謝野 晶子 (1878-1942). La obra en la que se encuentra esta crítica es Haiku kōza (俳句講 座) de 1932. Vid. Crowley, Cherryl Anne (2001): Haikai Poet Yosa Buson (1716-1783) and the Back to Bashō Movement. Tesis doctoral dirigida por Haruo Shirane, Escuela de Posgrado de Artes y Ciencias, Universidad de Columbia. p. 267-268.

17 Ibidem.

18 Para Cabezas cada uno de los cuatro grandes poetas del haiku adopta sobre una posición distinta sobre este arte: "Para Bashó el jaiku era ciertamente una ascesis a lo Zen. Para Buson, un arte cuyo fin era la belleza. Para Issa, una efusión emotiva de su humanísima y franciscana ternura hacia personas, animales y cosas. Para Shiki, 
y vigencia de esta idea que se ha convertido en un referente ineludible para quienes sostienen la convicción de la vía del haiku (haikudō 俳句同). ${ }^{19}$

Esto nos lleva a un principio fundamental para comprender el desarrollo del haiku, que es su identificación como vía o camino espiritual. Los rasgos de esta identificación no son fáciles de delinear ya que se encuentran en el entretejido de un sustrato de múltiples caminos espirituales del Este de Asia como el budismo zen y también las escuelas de la Tierra Pura (jōdō bukkyō 浄土仏教 ), el taoísmo y el confucianismo. Este sustrato fue bien entendido en Occidente por literatos como Blyth en su canónica antología Haiku (en cuatro volúmenes) de 1949. Hoy en día, entre todas las vías místicas o espirituales que se combinan en la vía del haiku, destaca por su popularidad aquella que identifica el haiku como testimonio de la práctica meditativa del budismo zen. Esta vía, que se atribuye mayormente a Bashō, ${ }^{20}$ conlleva la concepción del haiku como un arte del despertar interior o satori. Se trata de un sentimiento de gracia y visión de la realidad desde la no dualidad de formas, un estado de expresión profunda del mundo que brota de la sutil elocuencia. Este efecto es el que expresan autores como Shiki en su famoso poema de 1895:

\section{柿くへば＼cjkstart鐘が鳴るなり 法隆寺}

Kaki kueba

kane ga narunari

Hōryūji ${ }^{11}$

Comiendo kakis

replicó la campana

templo Hōryūji

Juan Manuel Cuartas Restrepo hace la siguiente interpretación de este poema:

"El haiku de Shiki es a propósito del sonido de la campana del Hōryūji, pero igualmente a propósito del mordisco que da a un kaki justo en el momento en que suena la campana [...] [es] tanta la emoción, la experiencia, los recuerdos despertados en un mismo evento, que no cometeríamos ninguna desfiguración al amplificarlo, sosteniendo, por ejemplo, como se discute hoy, que la campana a la que alude no era la del templo Hōryūji, sino la de Tōdaiji, sabiendo que en cualquier caso, a partir de este haikú, son todas las campanas del Japón, como todas las campanas del mundo las que dan ocasión a esa conjunción de la vida, la memoria y la escritura". ${ }^{22}$

admirador de Buson, una forma literaria y nada más.” CABEZAS, Antonio. Jaikus inmortales (2007): 8va edición, Madrid: Hiperión, p.11.

19 En español, esta visión es defendida principalmente por el traductor y poeta Vicente Haya.

20 Matsuo Bashō松尾 芭蕉 (1644-1694).

21 En adelante, las traducciones en español son de mi autoría. Cuando aplica he decidido reproducir el efecto rítmico tradicional de 5-7-5 moras en el español. Más adelante, he optado por hacer una traducción más experimental del haiku de ritmo libre. $C f$. La versión en inglés: "As I eat persimmon/ a temple bell resounds/ Hōryū-ji" en ADDIS, Stephen (2012): The Art of Haiku..., op.cit., p. 273.

22 Cuartas Restrepo, Juan Manuel (2005): Los siete poetas del haikú. Cali, Colombia: Universidad del Valle, p.179. 
Como se puede entender, la interpretación de Restrepo trae a la luz la idea del shasei de Shiki, tanto como su interpretación del haiku como el registro de un súbito estado de iluminación. Esta interpretación, y valoración, es la que suelen trasladar los críticos en Occidente a casi todos los haijin, tomando como modelo a Matsuo Bashō; y en cuanto a Bashō, este es el origen de la interpretación más popular en occidente del conocido haiku del estanque y la rana (Furu ike ya...) que identifica al poema como una observación "desnuda de subjetividad alguna" de la naturaleza y testimonio ejemplar del despertar o satori. Regresando a Shiki, podemos decir que su idea de shasei, que mantuvo en pie durante su larga convalecencia a causa de una tuberculosis que le impedía salir de su cuarto y luego aún caminar, se ha convertido en una de las rutas ejemplares de la vía del haiku:

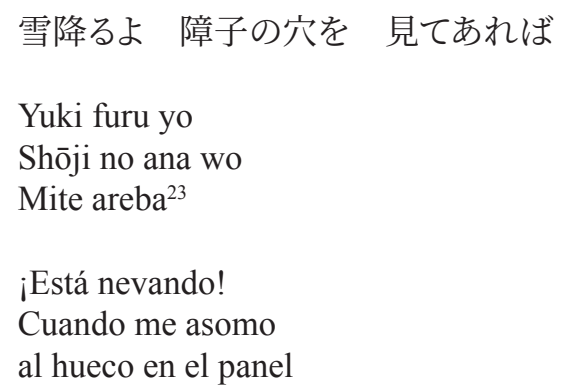

A la muerte de Shiki, en 1902, Takahama Kyoshi se convirtió en otra figura central del ambiente literario del haiku moderno. Como editor de la popular revista Hototogisu favoreció las nuevas tendencias de versificación fuera del patrón rítmico 5-7-5, de17 moras, aunque mantuvo una postura conservadora respecto al requisito de incluir palabras referentes a las estaciones llamadas kigo (季語). ${ }^{24}$ Otro poeta de la época, Kawahigashi Hekigotō, — originario de Matsuyama como Shiki- se convirtió en 1902 en editor de la columna de haiku del diario Nippon. Desde este espacio de comunicación masiva Kawahigashi proponía abandonar la regulación rítmica de las 17 sílabas, y se aventuró a componer en 26 sílabas. Por una parte, sus poemas buscaban una experiencia sensorial de disolución del color, siguiendo algunos de los preceptos propuestos por la escuela impresionista, ${ }^{25}$ por la otra, su obra en tarjetas verticales (tanzaku短冊) se caracteriza por su "excentricidad", de manera similar a como lo hicieron con las tipografías las vanguardias europeas.

Otro de los poetas del movimiento vanguardista de haiku, bautizado como "la nueva tendencia" (shin keikō haiku undō 新傾向運動) fue Ogiwara Seisensui, estudiante de letras alemanas en la Universidad Imperial de Tokio y fundador de la revista de vanguardia "Estrato nimbus" ("Sōun" 層雲). Seisensui promovió el abandono de la utilización de las palabras estacionales y la escritura del haiku con nuevos ritmos. Dos jóvenes poetas de entonces, Ozaki Hōsai y Taneda Santōka fueron seguidores y estudiantes del estilo de Seisensui. Como ríos paralelos, las vidas de Ozaki y Taneda estuvieron marcadas por el alcoholismo temprano, y luego, la búsqueda

\footnotetext{
23 Cf. "It's snowing/ I can see it through a hole/ in the paper window". Addis, Stephen (2012): The Art of Haiku..., op. cit., p. 276.

$24 \quad$ Ibid., p. 283.

$25 \quad$ Ibid., pp. 285-287.
} 
de una vía espiritual que los llevó a ordenarse monjes budistas, Ozaki en 1920 y Taneda en 1925. Ozaki se retiró a la isla de Shodoshima en la prefectura de Kagawa en donde continuó escribiendo haikus en medio de una vida sumida en la pobreza hasta su muerte en 1926. Santōka, sobreviviente de su amigo, fue a visitar la tumba de éste en su primer peregrinaje por Japón, que duró tres años (1926-1929). Ambos autores, exponentes de una poesía íntimamente ligada a la vida excepcional que llevaron (poesía-vida), requieren un estudio que excede los límites de este trabajo, por lo tanto, intentaré situar un punto de partida enfocándome en la poesía-vida de Taneda Santōka.

\section{Suplicio en la poética de Santōka}

La estética vanguardista del haiku libre, la naturaleza y el budismo se entrelazan en la vida atormentada de Santōka, y dan forma a su poética del esfuerzo, la cual puede caracterizarse como una oscilación entre los polos de la derrota y la superación espiritual. Sus diarios, siguiendo la gran tradición de los diarios poéticos japoneses (nikki bungaku 日記文学), nos dan un testimonio de los recorridos del poeta por el Japón y de las adversidades en su camino. Como apunta el crítico James Abrams: "Santōka fue un hombre que siempre estuvo en movimiento y nunca encontró la paz interior", ${ }^{26}$ para poetas posteriores a la Segunda Guerra Mundial como Nanao Sakaki, Santōka fue un ejemplo del artista romántico y sentimental. ${ }^{27}$ Sin embargo, su poesía no quedó ensombrecida por las anécdotas de su vida, ni limitada por una visión "fatalista" de sí mismo, ya que, en su cualidad oscilante, creó una poética excepcional de la sinceridad del corazón. Se trata de un tipo de poética que nos recuerda también la de los grandes maestros del haiku como Bashō, Buson e Issa. En una sociedad muy distinta a las de los maestros del periodo Edo, los poemas de Santōka brillan con luz propia y se han convertido en importantes referentes de los valores de la honestidad y la lucha de muchos japoneses ante la adversidad.

Taneda Santōka nació Nishibaryō, una localidad rural en la prefectura de Yamaguchi en 1882 y su nombre de pila era Shōichi. Su padre fue un campesino terrateniente que llevó una vida disipada y mantuvo numerosas amantes, dilapidando así el patrimonio de la familia. Cuando tenía 11 años su madre se suicidó arrojándose a un pozo y a partir de entonces fue criado por su abuela. Interesado en el arte poético, entró a estudiar al Departamento de Literatura de la Universidad de Waseda en 1902, pero al poco tiempo se acentuaron sus problemas económicos. La crisis familiar y el incipiente alcoholismo del joven Shōichi lo condujeron a una crisis nerviosa que lo hizo abandonar la universidad. Entonces, regresó a su pueblo natal, se casó con Satō Sakino y nació su hijo Ken. Durante esta etapa de su vida se convirtió en seguidor del haijin Ogiwara Seisensui y comenzó a colaborar en la revista Sōun (1913).

Algunos años después, en 1916, la familia Taneda se trasladó a Kumamoto (en Kyūshū). Sin embargo, Taneda no logró mantener un trabajo estable. Hacia 1924 Santōka había sido empresario de una destilería de sake junto a su padre, vendedor

26 Abrams, James (1977): "Mountain Tasting: Zen Haiku by Santōka Taneda. By Santōka Taneda and John Stevens" (reseña). En Monumenta Nipponica, vol. 32, nº. 3, Tokio, pp. 232-233.

27 Sakaki, Nanao (1999): "Cup of Tea, Plate of Fish” (entrevista con Nanao Sakaki). En Kobayashi, Issa (autor) / Sakaki (trductor): Inch by inch. 45 haiku by ISSA. New Mexico: La Alameda Press, p. 64. 
de libros usados, y bibliotecario en Tokio. Después del Gran Terremoto de Kantō de 1923, que devastó gran parte de Tokio, sintiéndose derrotado, decidió regresar a Kumamoto. En 1924, Santōka borracho, intentó suicidarse "plantándose de pie entre los raíles de un tren que avanzaba hacia él, pero el ferrocarril frenó a tiempo y fue arrojado afuera". ${ }^{28}$ En ese momento fue recogido por el prior de un templo zen de los alrededores: Gion Mochizuki Osho, prior del Hōonji. El prior lo invitó a permanecer en el templo y aprender meditación. Un año después, Taneda fue ordenado monje de la escuela Sōtō y le fue dado a su cargo el pequeño templo de Mitori Kannon-dō en las afuera de Kumamoto, lo cual afianzó la nueva vocación del poeta. Como monje se dedicaba a mantener la sala principal, tañer la campana al amanecer y al atardecer, y a mendigar por el vencindario..$^{29}$ Durante este periodo las enseñanzas budistas fueron forjando en él una vocación hacia la labor mendicante o takuhatsu, que dio comienzo a una nueva forma de vida como monje errante.

\section{しとどに 濡れてこれは 道しるべの石}

Shitodo ni nurete kore wa michishirube no ishi ${ }^{30}$

Mojada hasta los huesos... la piedra que señala el camino.

El poema anterior describe la sensación de máxima desnudez de una piedra que señala un camino. Podría decirse que la senda que comenzó a andar el monje-poeta, a partir de 1926, a los 44 años, fue también una lucha de autosuperación. Pero antes, hay que señalar que en la tradición budista del Japón la itinerancia forma parte del entrenamiento monástico de algunas escuelas, ya que durante el periodo en que los monjes se convierten en itinerantes van en busca de aprendizaje por otros templos y también realizando servicios. También hay que destacar que en Japón la itinerancia suele acompañar a rutas de peregrinación por circuitos antiguos que emulan el paso de los hombres santos o hijiri (聖). Un ejemplo muy conocido es el Shikoku henro ( 四国遍路) un circuito que se dice que fue fundado por el ilustrísimo Kūkai, fundador de la escuela Shingon. ${ }^{31}$ Estos circuitos forman parte de una tradición literaria, en la cual figuran poetas como Saigy $\overline{0}^{32}$ y Bashō; y también forman parte de recorridos turísticos que fueron popularizados en la época Edo. Así que, en un sentido general, se puede decir que la itinerancia en Japón es una actividad con múltiples capas de significación cultural, en las que se combinan entre otros asuntos, lo turístico, lo literario y lo religioso.

Durante su primer peregrinaje para "orar por el descanso del espíritu de su madre", Taneda visitó Shikoku, la cuarta isla en tamaño, famosa por su ruta de los 88

$\overline{28}$ Maillard, Chantall (2009): “Orinar en la nieve” (prólogo). En El monje desnudo:100 haikus, Madrid: Miraguano ediciones, p. XIII.

29 La labor mendicante (takuhatsu托鉢) tiene dentro del budismo una amplia tradición e importancia: "Proveer materialmente a la comunidad monástica, permitiendo a los monjes dedicar mayor tiempo a las actividades religiosos. La otra es brindar a los miembros de la comunidad laica una oportunidad de ganar mérito al donar comida, ropa o dinero a la orden" Vid. WATSON, Burton (2003): "Introduction". En For all my walking. FreeVerse Haiku of Taneda Santōka with Excerpts from His Diary. Nueva York: Columbia University Press, p. 6-7.

30 "Wet to the skin/ the stone here / pointing out the path", TANEDA, Santōka (autor) / WATson, Burton (trad.) (2003): For all my walking..., op.cit., p. 22.

31 Kūkai空海 (774-835), conocido póstumamente como el Gran Maestro que propagó la Doctrina Budista (Kōbō Daishi弓厶法大師)

32 Saigyō Hōshi西行法師 (1118-1190). 
templos (Shikoku o-henro 四国遍路). Estos viajes, a los que Santōka se refiere como gyōkotsu行乞 (la práctica de la mendicidad en el budismo) encierran también las ideas de la ligereza, la meditación y la transferencia de los méritos del monje por comida o dinero. Sin embargo, durante las turbulentas décadas de los treinta y cuarenta, la itinerancia del poeta monje dio paso también a un recorrido que describe la dura vida de los habitantes en el campo, tal como describe en sus diarios:

"En una jornada diaria de trabajo, sudando de la mañana a la noche, un hombre puede hacer 80 sen y una mujer hace 50 sen. Un fabricante de carbón gana por su trabajo de todo el día 25 sen máximo. Incluso alguien que pesca de manera eficaz en el río Kuma (famoso por sus peces ayu) puede ganar $70 \mathrm{u} 80$ sen por la pesca de todo el día. Obviamente, estas personas apenas si pueden mantenerse con vida. Ciertamente no disfrutan la vida. Cuando pienso en ello, la vida que yo tengo es mejor que la que merezco." ${ }^{\text {33 }}$

El pasaje anterior nos revela la compasión que sentía el poeta frente a una realidad social que no le era indiferente. Si la vida del monje mendicante siempre ha sido difícil, la de Santōka fue especialmente difícil en el clima social de la época; en una sociedad rural que cada vez se encaminaba más a la movilización para la guerra y que apenas sobrevivía al día. Bajo este horizonte, la vida escogida por Santōka parecía no sólo estar fuera de lugar, sino también desafiar el espíritu de la época que promovía el servicio al ente nacional (kokutai 国体) en favor de la libertad individual. Así, el poeta expresaba los motivos de su vida peregrina: "Para hacer lo que quiero, y no hacer lo que no quiero, ése es el motivo por el que adopté esta forma de vida". Sin embargo, esta marcha "a contracorriente de la época" también se vio mermada por una vida de excesos con el alcohol, que sembró en el poeta un sentimiento de duda espiritual, como lo expresa en uno de los pasajes de estas jornadas:

Octubre 30, 1930. Lluvia. Descanso en la posada.

Está lloviendo nuevamente. Nada que hacer sino tomar un descanso. Reposando todo el día. Cómo me gustaría llegar a Nobeoko tan pronto como sea posible, así podría recoger mi correo en la oficina postal, aunque ahora trato de olvidarme de ello. Bueno, al menos he podido realizar algunas lecturas y escribir algo, así que no ha sido tan mal día. Por alguna razón siento mi cabeza pesada, y mi estómago e intestinos también me duelen. Probablemente es la resaca del $s h \bar{c} c h \overline{\mathrm{u}}^{34}$ de la noche anterior, el primero que tomo desde hace tiempo. Ese fue el asunto, estoy seguro, me asombro de mí mismo:

Hoy por todo el día - no enojarse

Hoy por todo el día — no decir mentiras

Hoy por todo el día — no desperdiciar nada

Estos son mis Tres Votos.

No enojarse - es posible obedecer esta regla, al menos hasta cierto grado. No decir mentiras - Esta es una difícil. Significa no solo no decir mentiras con tu boca, sino no mentir en tu mente ni en tu corazón. Puedes estar sin mentir con la

33 Entrada del 16 de septiembre de 1930. Vid. TANEDA, Santōka (autor) / WATsOn, Burton (trad.) (2003): For all my walking..., op. cit., p. 32. (La traducción es del autor de este artículo.)

34 El shōchu 焼酎es un tipo de aguardiente destilado que puede fabricarse de arroz, camote, soba, entre otros. 
boca - probablemente - pero entonces también deberás hacerlo de tal manera de no mentir tampoco con el cuerpo. Lo que se dice "la práctica constante" de las enseñanzas budistas tiene que ser como el agua que fluye, como el soplo del viento. Si dejas que cualquier cosa te enoje cuando estás pidiendo la limosna, no vas a llegar a ninguna parte. Cuando la gente diga no o mire hacia otra parte, tienes que preguntarte que estás haciendo mal. Realmente, yo no tengo ninguno de los méritos para recibir limosnas, ahora que lo pienso... Estos días me fijo en el torpe e inepto estado de mi mente, así salgo a recibir cosas o mendigar y me siento avergonzando y alicaído.

En cuanto a no desperdiciar nada, sigo esta regla de manera general. Pero si fuera realmente serio, significaría hacer el mejor uso posible de cualquier cosa, y eso es extremadamente difícil. ¿Pongamos por ejemplo el sake - Me gusta el sake, así que no lo voy a dejar — no hay nada que hacer respecto a beber, — ¿pero entonces, cuánto mérito voy a conseguir de esto? ¡Y si dejo que el sake saque lo mejor de mí, entonces soy su esclavo, en otras palabras, un caso perdido!

Y esta lluvia que cae y cae $-\mathrm{y}$ ya sea que la gente ore o no ore por ella, continuará cayendo tanto como quiera. Sabemos que hasta el momento en que miremos al cielo y oremos con esperanza amainará. Esto es el corazón humano para mí. ${ }^{35}$

En el pasaje anterior, Santōka atribuye la falta de limosnas recibidas a las fallas en su comportamiento y se retrata a sí mismo como un aprendiz "fallido" y dominado por el alcohol. Esta manera de visualizarse, como alguien "sin méritos", halla una luz en la esperanza puesta en el corazón humano. Así, la fe, se convierte en el motor de una práctica "desde cero" para ser mejor: no enojarse, no decir mentiras y no desperdiciar nada, que son los votos del poeta. Estos valores y confesiones nos ayudan a comprender que se trata de una poética de autosuperación que no busca el modelo de los grandes ascetas, sino que describe el suplicio que puede significar el cultivo espiritual. Un tipo de suplicio particular, en el cual brilla como luz de esperanza el valor de la "sinceridad del corazón" que se requiere para ser una mejor persona; y que tendrá como escenario principal la andanza por la naturaleza.

\section{Santōka y la naturaleza}

Para situar una perspectiva ecocrítica en la poética de Santōka, quisiera contrastar ésta con otra poética del haiku, la del haijin Kobayashi Issa. ${ }^{36}$ Por un lado, Issa construyó en sus poemas y diarios una idea de la naturaleza que es como un vecindario íntimo en el cual los animales y demás seres animados son amigos, vecinos o familiares del poeta. En esta visión "del vecindario íntimo" el mundo natural aparece descrito a través de una visión ecocéntrica, o sea, desde una perspectiva en la cual la compasión budista hacia seres humanos y no humanos no está fundada en una posición jerárquica, es decir, todos los seres son sujetos de una misma compasión trascendente. Aunque se suele identificar al haiku como una vía espiritual fundada

\footnotetext{
35 Entrada del 30 de octubre de 1930. Vid. TANEDA, Santōka (autor) / WATSON, Burton (trad.), op. cit., p. 36-37. (La traducción es del autor de este artículo.)

36 Kobayashi Issa, 小林一茶 (1763-1828).
} 
en las prácticas e ideas del zen, hay que recordar que Issa fue ordenado monje de la escuela de la Tierra Pura o Jōdo Shinshū. Por el contrario, la visión de la naturaleza de Santōka permanece siempre centrada en su "individualidad" atormentada con tendencia a la autocompasión. No obstante, en la poética de Santōka, hay un rechazo al sentimiento de autocompasión que se convierte en el motor poético que confiere el sentido de prueba física y espiritual al mundo natural:

長生きの 蝿や蛋蚊や貧乏村
Nagaiki no hae ya nomi ka ya binbō mura. ${ }^{37}$

Ancianos son

moscas, pulgas y mosquitos

del pueblo pobre.

(Kobayashi Issa)

我ときて 遊べや親の ない雀

Ware to kite asobeya oyanonai suzume ${ }^{38}$

Ven a jugar

conmigo, pequeño

gorrión sin padres.

(Kobayashi Issa)

分け入っても 分け入っても 青い山

Wake itte mo wake itte mo aoi yama ${ }^{39}$

Mientras más me adentro...más me adentro... verdes montañas

(Taneda Santōka)

物乞ふ 家もなくなり 山には雲

Monogoi fu ie mo naku nari yama ni wa kumo ${ }^{40}$

no quedan casas para mendigar... nubes en la montaña

(Taneda Santōka)

37 "Flies, fleas, mosquitoes / And people — all long lived / in my poor village" KoBAYASHI, Issa (autor) / SAKAKI, Nanao (trad.) (1999): Inch by inch.45 haiku by Issa. New Mexico, Albuquerque: La Alameda Press, p. 39.

38 “Come play with me! / You, little sparrow / motherless sparrow!” KoBAYASHI, Issa (autor) / SAKAKI, Nanao (trad.) (1999): Inch by inch..., op. cit., p. 27.

39 “The deeper I go/ The deeper I go/ green mountains", TANEDA, Santōka (autor) / WATSON, Burton Watson (trad.), op. cit., p. 12.

40 "No more houses / to beg from/ clouds on the mountain", Ibidem. 
Si los poemas de Issa encumbran la igualdad del mundo natural frente a los ojos del Buda. En los poemas de Santōka, la prueba espiritual y física alcanza otras cumbres, en las cuales el ego atormentado del poeta busca desaparecer en el paisaje y se disuelve en la voz del poema-mundo. Este acercamiento al paisaje, parte de su experiencia como practicante meditación de la escuela zen, se complementa con un acercamiento sensual a la naturaleza, que expresa como una particularidad japonesa frente a Occidente: "20 de septiembre, 1930. Los occidentales tratan de conquistar las montañas. La gente del Este contempla las montañas. Para nosotros las montañas no son objetos de estudio científico sino un trabajo de arte. Pacientemente saboreo las montañas." ${ }^{.41}$ En sus momentos supremos, los haikus de Santōka nos dan la imagen de un individuo cuya vida se transparenta hasta volverse una con la de los demás seres de la naturaleza:

蛙に なり切つて 飛ぶ

Kawazu ni nari kitte tobu ${ }^{42}$

Volverse rana... iSaltar!

山のいちにち 蟻も あるいてるる

Yama no ichinichi ari mo aruite iru $^{43}$

Todos los días... en la montaña las hormigas también caminan

死んでしまへば 雑草 雨ふる

shinde shimaeba zassō ame furu ${ }^{44}$

cuando muera...caerá la lluvia...la yerba...

Los dos autores tienen poéticas muy distintas, pero es cierto que algunos haikus de Santōka reflejan la visión igualitaria de Issa del mundo natural como "un vecindario" compartido por hombres, animales, plantas y demás seres. La igualdad ante los ojos del Buda es la misma que aquella en los ojos del que despierta a la realidad. Sin embargo, como he sostenido, la poética de Santōka oscila alrededor de la visión de sí mismo, como lo expresan los tres poemas anteriores. Esta visión de la naturaleza en torno a sí mismo, se observa mejor en los diarios. Por ejemplo, en un pasaje con un profundo sentimiento de derrota en el cual el poeta se compara con un árbol hueco:

27 de noviembre, día despejado.

Hoy hace una buena mañana, me digo que es una buena mañana. Canto junto a los pajaritos.

Voy meditando, estoy haciendo un monólogo: la posibilidad de que exista una persona egoísta y alterable como yo es de una entre diez millones, algo que no debería ser. Soy lo que se dice como un árbol seco en la montaña.

\section{Ibidem.}

42 Addis, Stephen (2012): The Art of Haiku ..., op. cit., p. 297.

43 Ibid., p. 296.

44 Addis, Stephen. En Haiku of Taneda Santōka translated into English, French, German, Spanish organized by Romaji, in alphabetical order. [Página Web] Terebess Asia Online (TAO). Disponible en http://terebess.hu/ english/haiku/taneda.html (Consultado el 10 noviembre, 2016) 
Por la tarde, me dolía tanto la cabeza, que salí a caminar a cualquier parte. ¡Oh! enrojecidas por el otoño, la belleza de las hojas, de los árboles de cera. Y corté nuevamente una rama. ¡Oh, los recuerdos de mi madre! Si escribiera una autobiografía, éstas serían mis palabras de apertura: "La desgracia de mi familia empezó con el suicidio de mi madre". Algo así es lo que tendría que escribir, sin embargo, no fue tu culpa, madre, tú sólo fuiste una víctima. Por la mañana, la tarde y la noche cernías la harina de sarraceno para comer. Cuando aclaraba la noche despertabas, cuando oscurecía el día dormías, y entonces mi vida no era mala sino emocionante..$^{45}$

El pasaje anterior, escrito en prosa poética, nos ayuda a subrayar el sentimiento de autocompasión del poeta. Un sentimiento que moldeó su visión de la naturaleza como un lugar de prueba para forjar un ser humano mejor y más fuerte. La poética de Santōka, inseparable de su experiencia de vida, es un canto en el claroscuro entre la victoria y la derrota; la primera aparece como la cumbre del instante contemplativo, la segunda como el sentimiento más hondo de culpa. En este frágil balance, se encuentra su visión de la naturaleza como un territorio para poner a prueba la autosuperación y encumbrar el espíritu contemplativo. Así, de una manera distinta a la de Issa, el mundo natural gana prestigio en sus poemas y se convierte en fuente de un lenguaje espiritual para expresar su camino en búsqueda de un interior profundo y vivo (Mientras más me adentro...más me adentro... verdes montañas).

\section{Conclusiones}

Primero, la génesis del haiku de ritmo libre encierra los ideales de cambio y adaptación de un periodo de transición en la historia literaria japonesa que forzó a la relectura del haiku tradicional para que éste pudiera sobrevivir, e incluso superar, a la competencia de formas literarias y artísticas del Occidente. El gran protagonista, pero no el único, de estos ideales fue Masaoka Shiki, cuyas ideas, sustentadas por una entereza vital, se popularizaron dentro y más allá de Japón, hasta el punto de que las ideas del shasei y de testimonio del despertar súbito (satori) se han convertido en dos pilares del discurso del haiku como vía espiritual (haikudō). Dos pilares sobre los cuales se ha construido varias interpretaciones de este arte o vía en nuestra lengua.

Segundo, esta genealogía que va de Shiki a Santōka, puede verse como la semilla de un árbol que fructifica en el haiku del verso libre que se popularizó. La razón del exitoso enraizamiento de toda la genealogía se debe a la calidad literaria del propio Shiki, así como la de sus descendientes poéticos, que convirtieron cada impulso renovador en nuevas cimas literarias. Por ello, la poética de Santōka es como un fruto que contiene el sabor del haiku como vía espiritual. Sin embargo, son múltiples los rasgos y matices de estas vías espirituales del haijin.

45 La traducción es mía. TANEDA, Santōka. Entrada del 27 de noviembre de 1938. En Gochū nikki 其中日記（十 一) 1938. Disponible en http://www.aozora.gr.jp/cards/000146/files/49605_37002.html. Numerosos diarios de Taneda Santōka en japonés pueden consultarse libremente en Aozora Intanetto Denshitoshokan, disponibe en http://www.aozora.gr.jp/index_pages/person146.html\#sakuhin_list_1 
Desde un punto de vista ecocrítico, James Abrams ${ }^{46}$ acierta al decir que Santōka fue primeramente un poeta atormentado. Sin embargo, es necesario destacar, que el tormento, en tanto se convierte en motor de búsqueda de la autosuperación, puede ser un elemento en la vía espiritual de lo que Blyth ha llamado el "camino de regreso a la naturaleza". Aparte de eso, tampoco creemos que se trate del último poeta que encarna los ideales del poeta-monje itinerante. Como hemos visto, la genealogía del haiku de ritmo libre es movimiento de transformación con el cual la cultura japonesa incorpora lo nuevo y externo para continuar creciendo. Aunque Santōka vivió en una época en la cual muchos aspectos de la cultura espiritual japonesa se encontraban en decadencia, su vida atormentada por el alcohol refleja el claroscuro vital de muchos de los artistas japoneses de todas las épocas: un movimiento entre la desventura personal y el éxtasis contemplativo. Este claroscuro es una característica que Santōka comparte con otros escritores de su época como Akutagawa Ryūnosuke y Miyazawa Kenji, autor del famoso poema ame ni mo makezu (雨ニモマケズ).

Quiero subrayar que en su relevancia poética hacía falta poner por delante la creación de un lenguaje del esfuerzo basado en la sinceridad del corazón, un lenguaje original que tiene por escenario y fuente de inspiración la naturaleza. Al igual que en la obra del poeta de Iwate, la poesía de Santōka fructificó en la sensibilidad contemporánea para expresar la lucha oscilante entre la celebración y la derrota, el sentimiento de culpa y la disolución contemplativa. Así, los poemas de Santōka nos conmueven por su desnudez, con su excéntrica mezcla de espíritu enérgico, pero a la vez delicado y abierto a reconocer sus debilidades.

Finalmente, esta valoración de su poética, a la vez puede nutrirse de la comparación ecocrítica, que permite aclarar que poetas con motivos y posiciones distantes como Issa y Santōka, en sus mejores versos nos comunican una visión espiritual de la naturaleza en la cual seres humanos y otros seres coexisten en un mismo nivel, que es el de la no separación esencial entre el ser humano y la naturaleza en la mirada atenta de un iluminado. El aporte de Santōka refuerza un viejo puente dentro de la poesía japonesa en el cual la naturaleza gana una posición de prestigio como escenario de prueba religiosa y depósito del lenguaje poético sobre el camino de la autosuperación.

La singularísima poesía-vida de estos haijin, de Shiki a Santōka, apuntala la idea de que el poeta se encarga de actualizar y renovar las tradiciones con el lenguaje. La singular mezcla, muy presente en la literatura japonesa, que entreteje el mundo y la vida a la luz de una época turbulenta, nos permite aventurar algunas razones de su popularidad actual: El valor social de la poética de la superación y el esfuerzo, por ejemplo, para los sobrevivientes de la Segunda Guerra Mundial, y en época más reciente para los sobrevivientes de los desastres naturales como el terremoto y tsunami del 2011 (y en este sentido, los poemas de Santōka, no limitan su popularidad a estos sucesos, ya que en realidad se han convertido en lemas que aparecen en todo tipo de literatura de superación personal). Así, no es de menospreciar el valor que puede tener la visión de la naturaleza como un territorio de trabajo arduo, pero de transparencia espiritual, en donde es posible sobreponerse a las zonas oscuras de la vida y salir adelante.

$46 \quad C f$. Abrams, James (1981): "Mountain Tasting: Zen Haiku by Santōka Taneda. By Santōka Taneda and John Stevens" (reseña). En Monumenta Nipponica, vol. 36, n 2, Tokio, pp. 232-233. Y del mismo autor (1977): "Hail in the Begging Bowl. The Odyssey and Poetry of Santōka”. En Monumenta Nipponica, vol. 32, nº 3, pp. 269-302. 